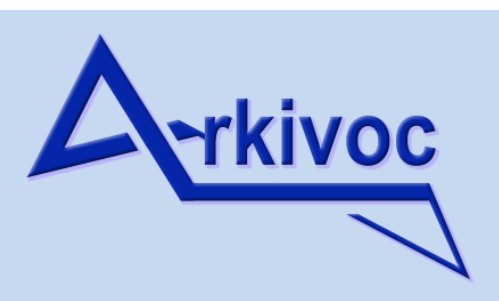

Free to Authors and Readers
A Platinum Open Access Journal for Organic Chemistry
Review

DOAJ Seal

Arkivoc 2021, part i, 143-161

\title{
Asymmetric reactions involving isobenzopyrylium ion intermediates
}

\author{
Hongbing Lan, ${ }^{a}$ Shuyan Yu, ${ }^{* a, b}$ Hengyu Qian, ${ }^{a}$ Weiyi Zhao, ${ }^{a}$ and Zhigang Yin*a \\ aMaterial and Chemical Engineering College, Zhengzhou University of Light Industry, \\ Zhengzhou 450002, Henan, P. R. China \\ ${ }^{b}$ Henan Engineering Research Center of Catalysis and Separation of Cyclohexanol, Zhengzhou University \\ of Light Industry, Zhengzhou 450002, Henan, P. R. China \\ Email: yushuyan zzuli@163.com; yinck@zzuli.edu.cn
}

Received 12-08-2020

Accepted 01-22-2021

Published on line $02-20-2021$

\section{Abstract}

Isobenzopyrylium ions are highly reactive intermediates which have wide applications in synthetic chemistry. A range of catalytic reactions based on isobenzopyrylium, such as 1,2-nucleophilic addition, [4+2] and [3+2] cycloaddition provide a powerful protocol for constructing complex natural and unnatural products. Their asymmetric variations have been less explored, possibly owing to the lack of coordination sites within their planar structures. This mini-review summarizes the asymmetric transformations developed involving isobenzopyrylium ion intermediates. These works are arranged according to the reaction types. The catalytic systems and reaction mechanisms are described.

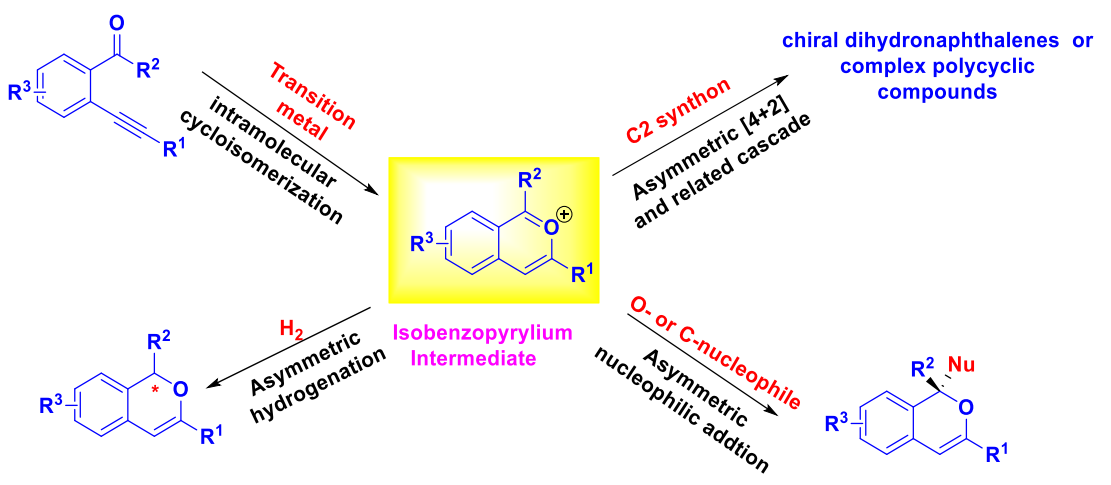

Keywords: Isobenzopyrylium, [4+2]-cycloaddition, asymmetric hydrogenation, nucleophilic addition, cascade reactions 


\section{Table of Contents}

1. Introduction

2. Asymmetric [4+2] Cycloadditions and Related Cascade Reactions

3. Asymmetric Hydrogenation

4. Asymmetric Nucleophilic Addition

5. Conclusions

6. Acknowledgements

7. References

\section{Introduction}

Isobenzopyrylium ion, a unique type of Hückel aromatic oxonium intermediate, attracted great attention in recent years owing to versatile chemical properties and synthetic applications. ${ }^{1-2}$ These highly reactive intermediates were originally obtained by dehydration of isocoumarin derivatives or condensation of orthoacylphenylacetones (Scheme 1A and 1B). ${ }^{3}$ Both of these methods suffered from the limited availability of the starting materials and unsatisfactory reaction yields. In 2002, Yamamoto's group found that isobenzopyrylium ions could be conveniently produced in situ as inseparable intermediates by the treatment of 0 alkynylbenzaldehydes with $\mathrm{AuCl}_{3} \cdot{ }^{4-8}$ Then other transition metal catalysts $\left(\mathrm{CuX},{ }^{9-10} \mathrm{~W},{ }^{11-14} \mathrm{PdX}_{2},{ }^{15-17} \mathrm{PtX}_{2}{ }^{18-22}\right.$ $\mathrm{Rh}(\mathrm{I})^{23}, \operatorname{In} \mathrm{X}_{3}{ }^{24-26}$ etc.) and electrophilic activators $\left(\mathrm{I}_{2},{ }^{27-29} \mathrm{IPy}_{2} \mathrm{BF}_{4},{ }^{30-32} \mathrm{TfOH}^{33-35}\right.$ etc.) proved to be effective in the intramolecular cycloisomerization of o-alkynylaryl carbonyl compounds (Scheme 1C). Furthermore, Yao and his co-workers reported in 2009 the isolation of storable and stable isochromenylium tetrafluoroborates (ICTBs) (Scheme 1D). ${ }^{36}$

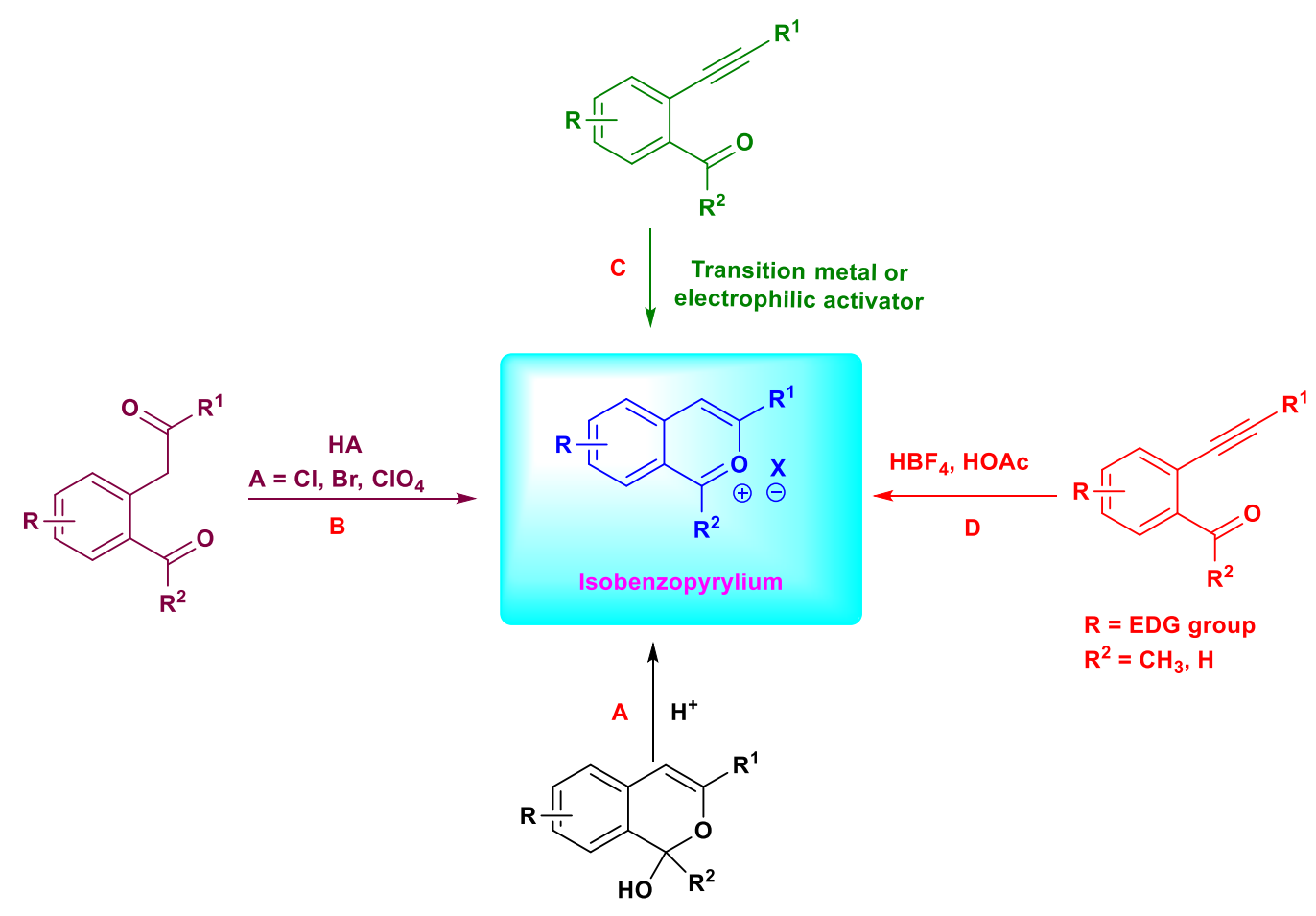

Scheme 1. Methods for the generation of isobenzopyryliums. 
Since its discovery, the rich chemistry of isobenzopyrylium has been amply demonstrated in the literature, and has provided a powerful protocol for constructing complex natural and unnatural products. The reported reactions included 1,2-nucleophilic addition, [4+2] cycloaddition, [3+2] cycloaddition and various cascade reactions. ${ }^{37-44}$ The asymmetric transformations of isobenzopyrylium ions have been less explored. ${ }^{45}$ This may be because the planar $10 \pi$-electron aromatic structure of the isobenzopyrylium ion lacks an obvious coordination site for a chiral catalyst which is often crucial for achieving high stereoselectivity. Their highly reactive properties also increased the difficulty in obtaining ideal enantioselective results.

This mini-review summarizes the asymmetric transformations involving isobenzopyrylium intermediates. The works are organised according to the different reaction types, aiming to encourage chemists to think about such cation intermediate from different points of view, thereby identifying new enantioselective transformations with these species.

\section{Asymmetric [4+2] Cycloaddition and Related Cascade Reactions}

The first asymmetric transformation of isobenzopyrylium was achieved by Tanaka's group in $2009 .{ }^{46}$ Prior to that, this group had discovered a highly enantioselective annulation of 2-alkynylbenzaldehydes $\mathbf{1}$ with isatins $\mathbf{2}$ catalyzed by a cationic rhodium(I)/chiral bisphosphine complex. ${ }^{47} \mathrm{~A}$ variety of spirocyclic isatin derivatives $\mathbf{3}$ were obtained in good yields with high ee values. These spiro-compounds were believed to be formed through the [4+2] cycloaddition of carbonyl compounds $\mathbf{2}$ with five-membered acylrhodacycle intermediates 2B, which were formed by the intramolecular addition of a rhodium hydride species $2 \mathrm{~A}$ to the pendant alkyne group (Scheme 2a). Both alkyl- and aryl-substituted 2-alkynylbenzaldehydes could react smoothly with $\mathrm{N}$-protected or $\mathrm{NH}$-free isatin. However, when 2-alkynylbenzaldehyde with a cyclohexenyl group at the alkyne terminus was tested, a moderate yield of tetrasubstituted (helical) alkene $\mathbf{4}$ was unexpectedly isolated along with a small amount of the expected spirocyclic isatin $\mathbf{3}$ (Scheme $2 \mathrm{~b}$ ). The reaction selectivity could be greatly improved through a change of chiral ligand ( $L 2$ vs $L 1,99: 1$ vs 3:2 ratio). After further optimization, the authors found addition of $\mathrm{AgBF}_{4}$ and $\mathrm{PPh}_{3}$ was beneficial for the formation of chiral tetrasubstituted alkenes 4 (Scheme 3). A possible reaction pathway was proposed as follows: the intramolecular cyclization of 2alkynylbenzaldehydes 1 under the activation of $\pi$-electrophilic cationic transition-metal complex generated isobenzopyrylium intermediate $\mathbf{3 A}$, which reacted with the $\mathrm{C}=\mathrm{O}$ bond of $\mathrm{N}$-methylisatin 2 via [4+2] enantioselective cycloaddition pathway to form ketoaldehyde $\mathbf{3 C}$ through adduct intermediate $\mathbf{3 B}$. Enantioselective intramolecular ketone hydroacylation of $3 \mathrm{C}$ proceeded through rhodacycle 3D to furnish the desired tetrasubstituted alkene 4. Control experiments suggested $\mathrm{AgBF}_{4}$ was necessary for good yields. It was believed to promote the $\pi$-electrophilicity of the cationic rhodium(I) complex, which is essential for the formation of intermediate $\mathbf{3 A}$. But its precise role is not clear at present. $\mathrm{PPh}_{3}$ was envisaged to occupy free coordination sites of the rhodium catalyst, with the result of preventing the interaction of rhodium with $\mathrm{AgBF}_{4}$. This interaction was believed to lower the catalytic activity towards both $\pi$-and $\sigma$-bond activation. With the optimal reaction conditions, a variety of tetrasubstituted helical alkenes $\mathbf{4}$ were obtained in good yields with excellent enantioselectivities, which might be applied to light-driven molecular motors, owing to their fascinating switching properties under UV irradiation. ${ }^{48}$ 


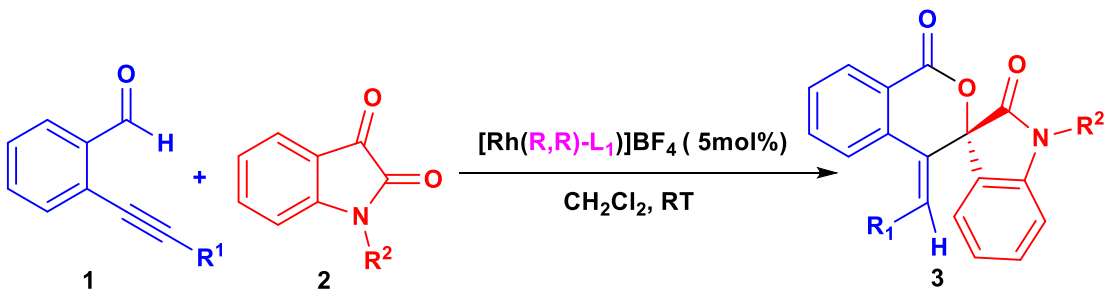

$\mathbf{R}^{1}=$ alkyl or aryl, $\mathbf{R}^{2}=\mathrm{H}$, Me or $\mathrm{Ph}$

a)

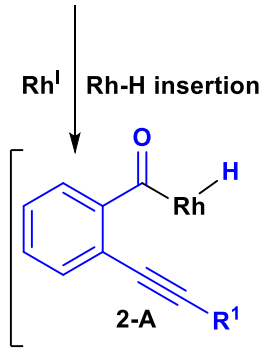

$73 \%-97 \%$ yield, $92 \%->99 \%$ ee
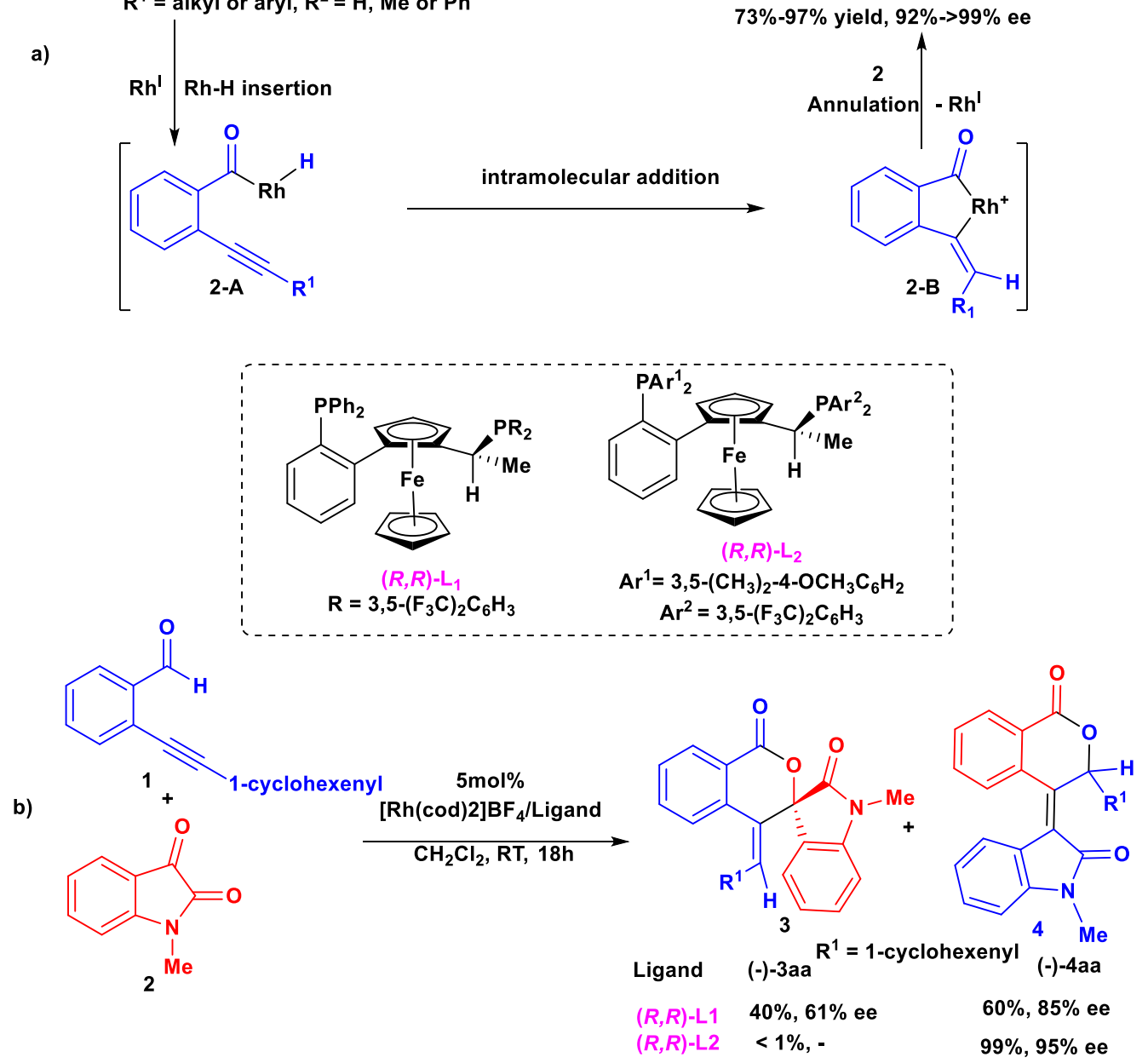

Scheme 2. Different reaction results of 2-alkynylbenzaldehydes with isatins. 

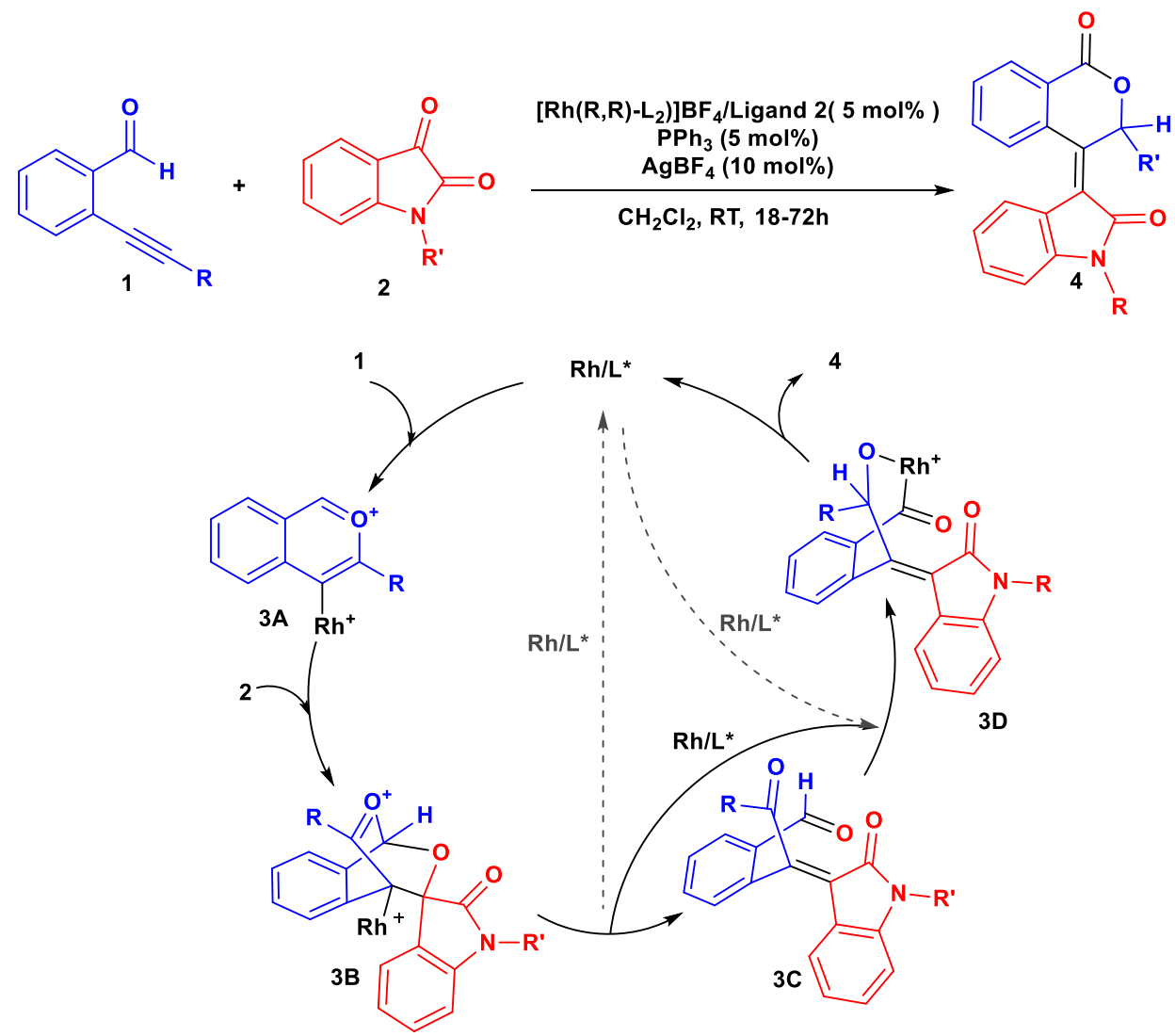

Scheme 3. Asymmetric [4+2] cycloaddition of isobenzopyrylium with isatins.

Following the interest in exploring the chemistries of isobenzopyrylium salts, many cascade transformations based on [4+2] cycloadditions were found to show high efficiency in constructing complex multiring structures with multiple stereogenic centers. In 2013, Yao's group reported an asymmetric cascade annulation between 2-hydroxystyrenes and in situ generated isobenzopyrylium intermediates based on the enantioselective [4+2] cycloaddition by cooperative binary catalysis of $\mathrm{Pd}(\mathrm{OAc})_{2}$ and chiral phosphoric acid (CPA-1, S-Trip). ${ }^{49}$ The developed method could construct a chiral tetrahydronaphthalene framework in a highly efficient manner. Such a skeleton represents a new type of conformationally constrained analog of podophyllotoxin (PPT), a well-known anticancer natural drug lead. ${ }^{50,51}$ Mechanistic investigation suggested that the counter-anion of $\mathrm{Pd}(\mathrm{II})$ was very important for the reaction $\left(\mathrm{AcO}^{-} \mathrm{vs} \mathrm{Cl}^{-}\right.$) (Scheme 4a), and the orthophenolic hydroxyl group in the styrene substrate was also essential to achieve this type of highly enantioselective cascade transformations (Scheme $4 \mathrm{~b}$ ). Based on these results, a possible reaction pathway was proposed (Scheme 5). Firstly, the alkyne bond of o-alkynylbenzaldehyde 5 was activated by $\mathrm{Pd}(\mathrm{OAc})_{2}$ to faciliate the intramolecular cycloisomerization, affording $\mathrm{Pd}(\mathrm{II})$-isobenzopyrylium intermediate 5A. The suitable anion of the isobenzopyrylium salt favored the anionic exchange with (S)-Trip. The resulting intermediate 5B linked with the 0 -hydroxystyrene 6 through hydrogen-bond between the phenolic $\mathrm{OH}$ of the styrene and the $\mathrm{P}=\mathrm{O}$ of Trip to assemble a highly ordered supramolecular assembly transition state. Then "intramolecular" asymmetric [4+2]-cycloaddition generated carbocation 5C, which was quickly trapped by the internal phenol hydroxyl to provide 5D. Finally, the protonation of 5D with HOAc delivered product 7 and regenerated the metal catalyst $\mathrm{Pd}(\mathrm{OAc})_{2}$. The high degree of enantioselectivity was considered to stem from both the steric hindrance of the bulky 1,3,5-triisopropylphenyl group of (S)-Trip moiety and the hydrogenbond interactions between the phenolic hydroxyl group of substrate 6 with the $P=O$ functionality of $(S)$-Trip. 
a) Control experiments of the cooperative catalysis

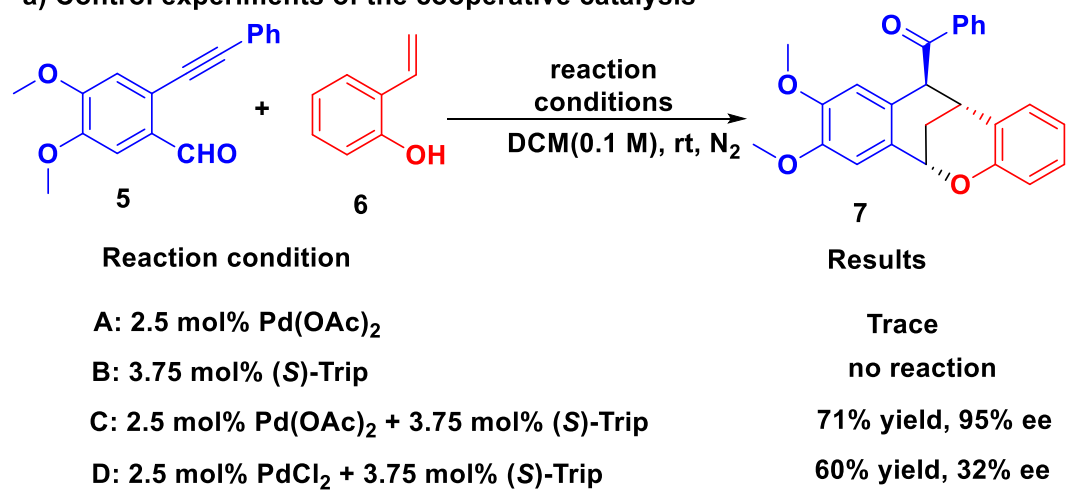

b) Control experiments for the role of ortho-phenolic hydroxyl functionality of 6

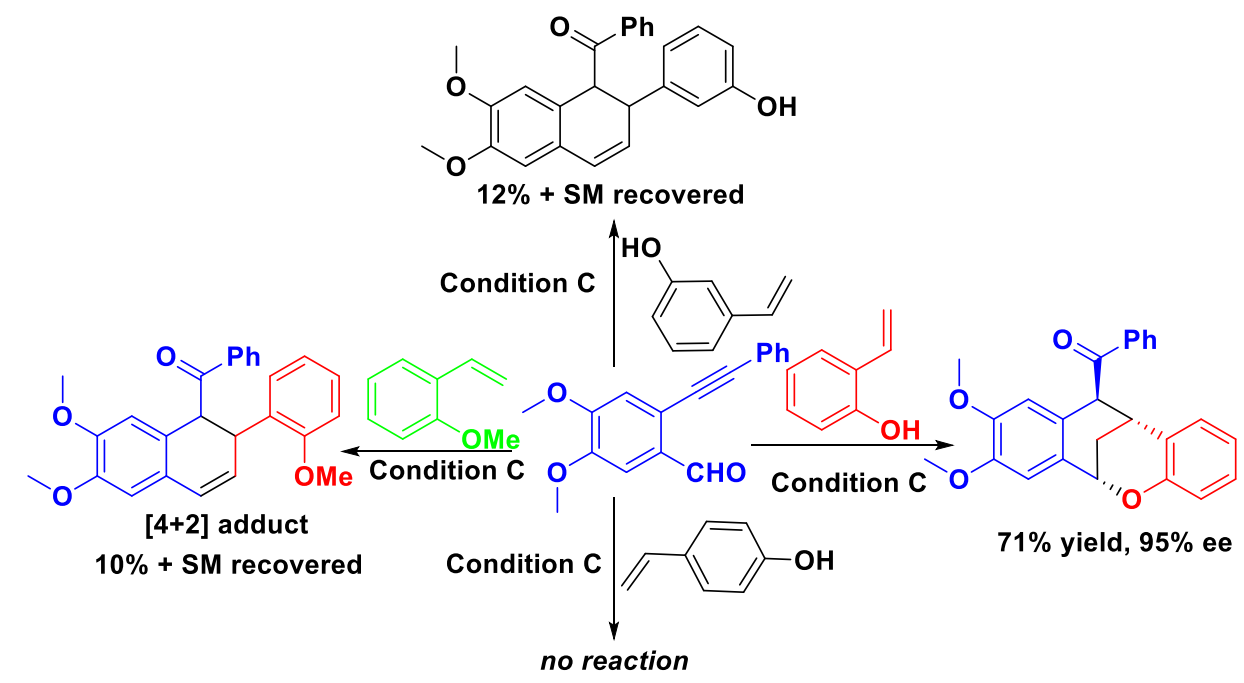

Scheme 4. Control experiments for the investigation of mechanism.

1,2-Dihydronaphthalenes represent an important structural motif in many natural products and biologically active molecules. ${ }^{52,53}$ They are also important synthetic intermediates toward various tetrahydronaphthalene molecules. Consequently, many strategies have been developed for their synthesis (achiral or racemic). ${ }^{54-56}$ However, regarding their asymmetric synthesis, for a long time the traditional dearomatization of electron-deficient naphthalene has been the major approach. It not only suffers from limited substrate scope (electron-deficient) but also requires the use of either chiral auxiliary or stoichiometric chiral ligands. ${ }^{57,58}$ Indeed, truly catalytic asymmetric approaches remain few. In 2015, the Sun group disclosed an organocatalytic enantio- and diastereoselective synthetic method for 1,2-dihydronaphthalenes based on the [4+2] cycloaddition of isobenzopyrylium intermediate with boronic acid (Scheme 6). ${ }^{59}$ In this work, acetal 8 was chosen as isobenzopyrylium precursor. Obviously different from other asymmetric transformation of isobenzopyrylium, this excellent asymmetric induction is achieved for the first time without an anchoring group or a metal catalyst in the 4-position of isobenzopyrylium. Only by treatment with chiral phosphoric acid (CPA-2), did the elimination of the alkoxy group from acetal 8 afford an isobenzopyrylium intermediate and generate a well-organized cyclic counteranion in the process, which was formed in situ by the combination of the leaving alkoxy group, the boronic acid $\mathbf{9}$ and the chiral phosphate. Such an unusual chiral counteranion served as a reactive nucleophile with chiral moiety in close proximity to react with isobenzopyrylium intermediate in sufficient chiral induction manner. Then the resulting bicyclic zwitterion underwent intramolecular elimination to give the desired dihydronaphthalene product $\mathbf{1 0}$ with satisfactory selectivity. 
The authors believed that excellent enantioselectivity was attributed to the well-organized cyclic counteranion.

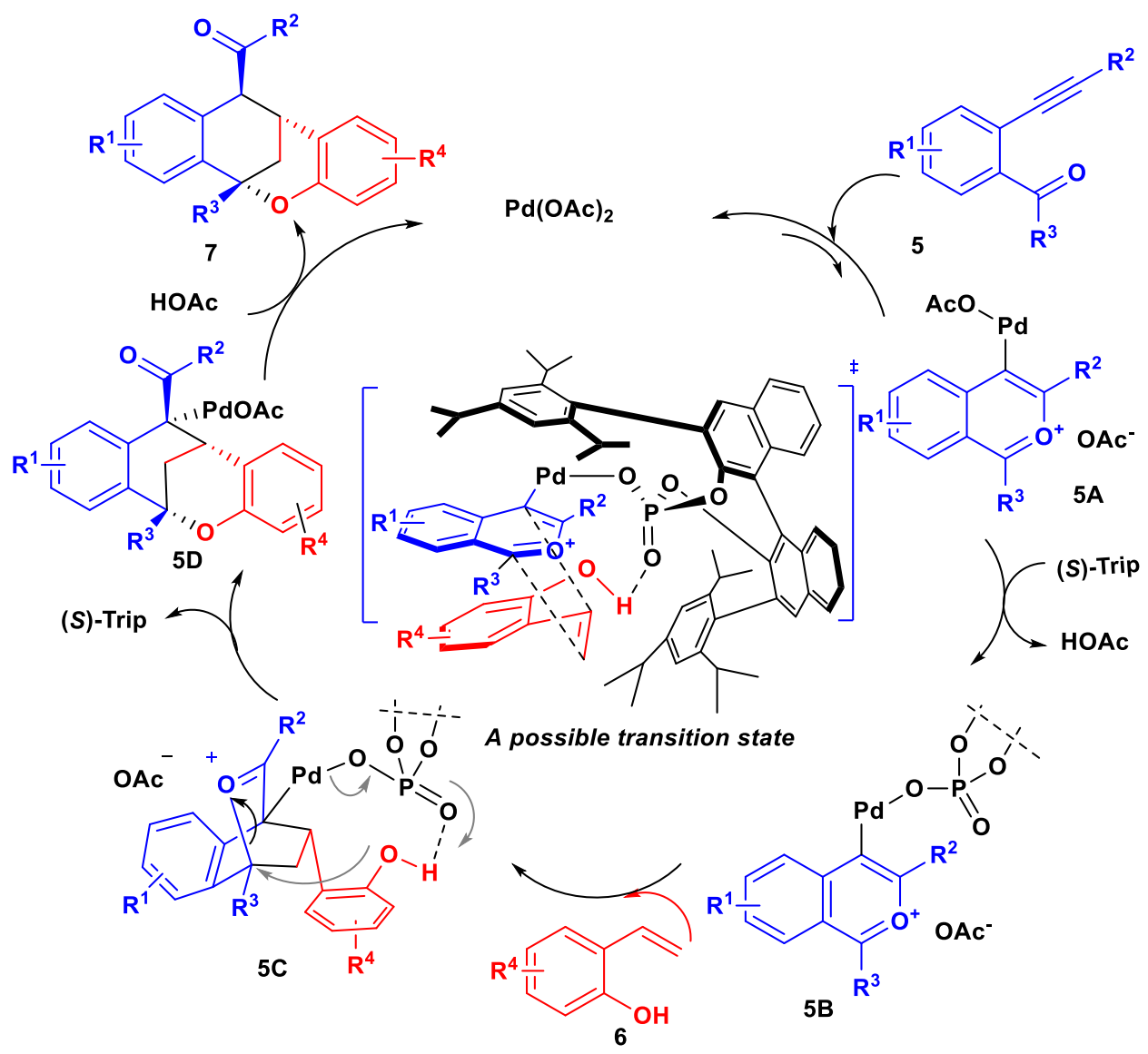

Scheme 5. Possible mechanism of cascade reaction based on [4+2] cycloaddition.

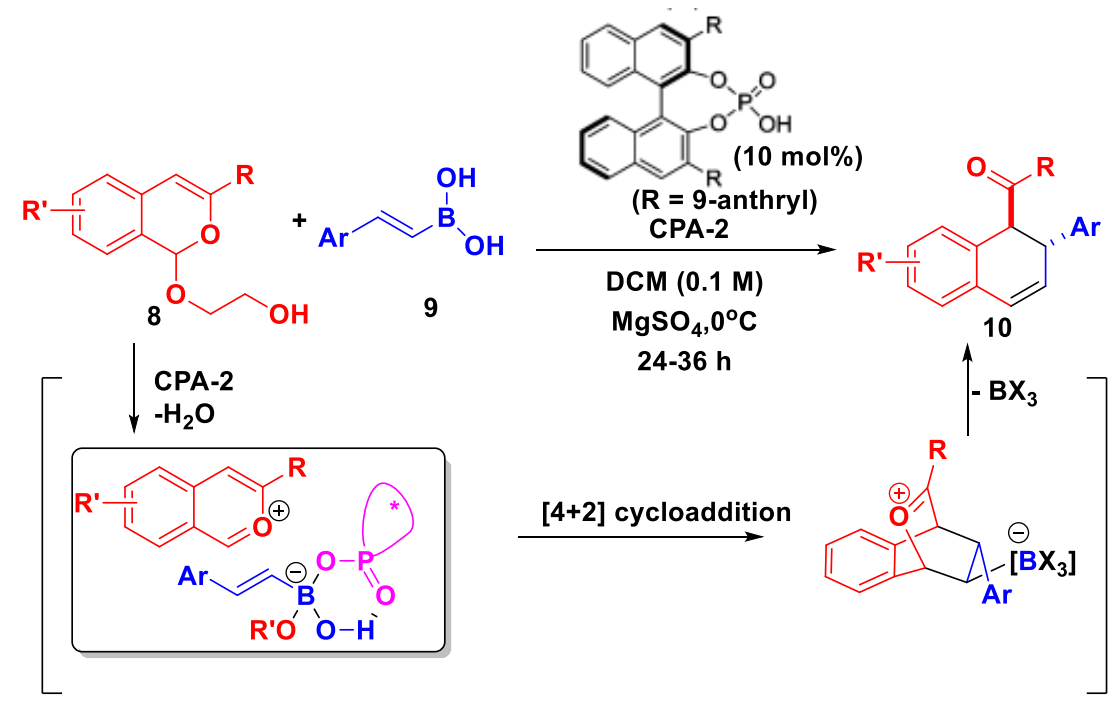

Scheme 6. Asymmetric [4+2] cycloaddition of isobenzopyrylium with boronic acid. 


\section{Asymmetric Hydrogenation}

1-Substituted-1H-isochromenes are an important class of heterocyclic compounds because of their fascinating biological and pharmacological activities. ${ }^{60-62}$ Among the methods for constructing such types of oxygencontaining heterocycles, the cycloisomerization of $o$-alkynylaryl alcohols is one of the most reliable and atomeconomic. ${ }^{63-64}$ Nevertheless, the enantioselective version of this reaction has rarely been reported. In 2013, Akiyama and co-workers developed an alternative method for chiral 1-substituted-1H-isochromenes through the copper(II) phosphate-catalyzed intramolecular cyclization/asymmetric transfer hydrogenation sequence of o-alkynylacetophenone by asymmetric counterion-directed catalysis (ACDC). ${ }^{65}$ Since the term was coined in 2006 , the use of enantiomerically pure counteranions for the induction of asymmetry in reactions proceeding through cationic intermediates has emerged as a powerful tool for a range of asymmetric transformations and greatly promoted by the incorporation of chiral binaphthyl phosphoric acids. ${ }^{66,67}$ Inspired by these great success, the Akiyama group surmised that intramolecular 6-endo-dig cycloisomerization of o-alkynyl acetophenone $\mathbf{1 1}$ activated by transition metal could afford a cationic metallic isobenzopyrylium intermediate, which could form a tight ion pair with the chiral phosphate counteranion to subsequently induce the desired asymmetric hydrogenation (Scheme 7). After careful screening of reaction conditions, this asymmetric sequence was achieved by the catalysis of copper(II)/ chiral phosphate which formed in situ from Cu(OTf) 2 , $\mathrm{Ag}_{2} \mathrm{CO}_{3}$ and chiral chiral phosphoric acid (CPA-3). With the stereocontrol of chiral counteranion, chiral 1substituted-1H-isochromenes containing various substituents were obtained in high yields with good to excellent enantioselectivities with Hantzsch esters as hydrogen source.

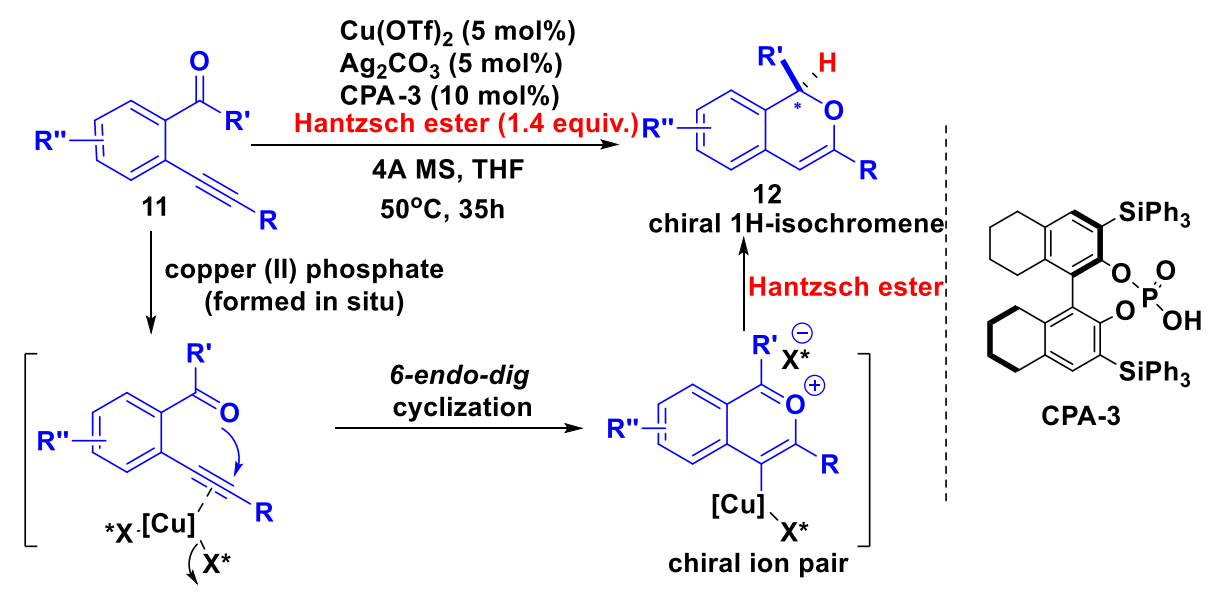

Scheme 7. Asymmetric hydrogenation of isobenzopyrylium by the catalysis of ACDC.

At almost the same time, the Terada group reported the chiral silver phosphate catalysed enantioselective transformation of ortho-alkynylaryl ketones into $1 \mathrm{H}$-isochromene derivatives by ACDC. Different from Akiyama's work, this intramolecular-cyclization/enantioselective-reduction sequence was conducted with the chiral silver phosphate prepared in advance from $\mathrm{Ag}_{2} \mathrm{CO}_{3}$ and the corresponding binol-derived phosphoric acid. ${ }^{68}$

Recently, the Fan group's work has shown that cationic ruthenium complexes of chiral monosulfonated diamines are very efficient catalysts for the asymmetric hydrogenation of various $N$-heteroaromatic compounds. ${ }^{69-71}$ Encouraged by these findings, the authors attempted to use these catalysts for the asymmetric hydrogenation of the highly reactive isobenzopyryliums. Because isobenzopyryliums were often 
generated in situ by treatment of ortho-alkynylaryl ketones with various metal catalysts, it was thus important to find two compatible catalysts for the overall reaction that also controlled the chemoselectivity and enantioselectivity. After optimization of reaction conditions, they successfully developed tandem catalysis with a binary system consisting of $\mathrm{Cu}(\mathrm{OTf})_{2}$ and chiral cationic ruthenium-diamine complex 13 (Scheme 8). ${ }^{72}$
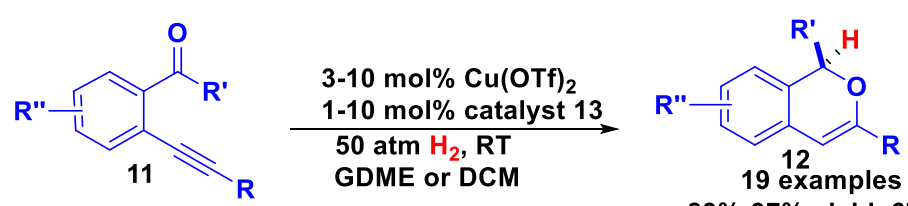
$83 \%-97 \%$ yield, $67 \%-94 \%$ ee

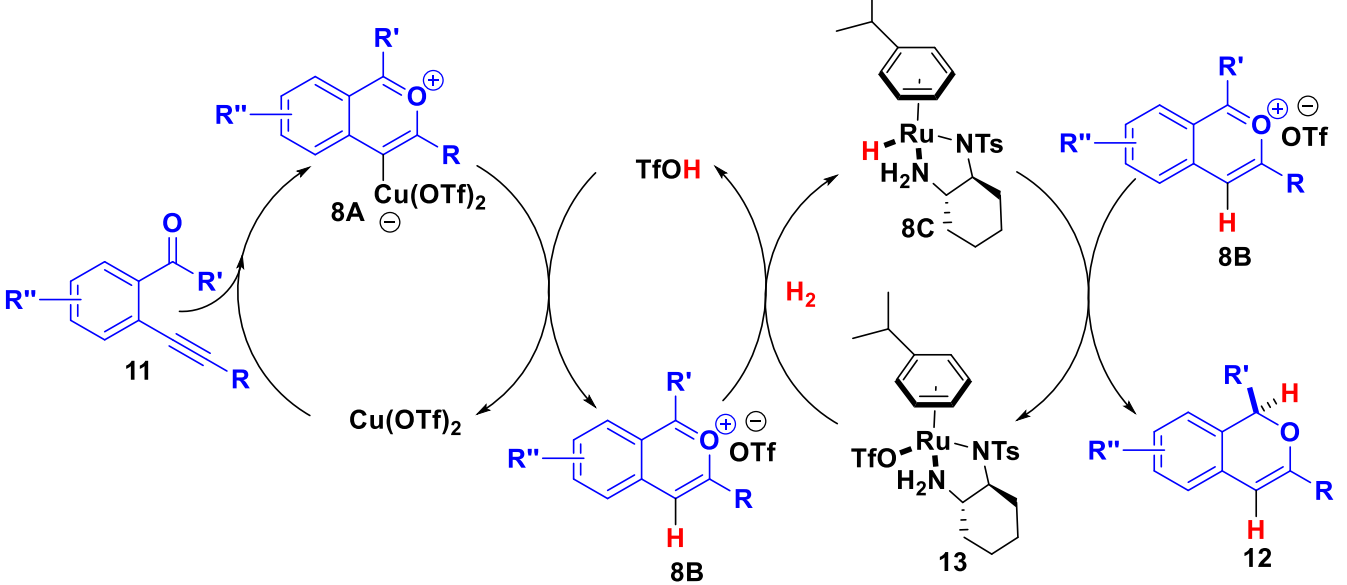

Scheme 8. Asymmetric hydrogenation of isobenzopyrylium by tandem catalysis.

Activated by $\mathrm{Cu}(\mathrm{OTf})_{2}$, the intramolecular cyclization of ortho-alkynylaryl ketone 11 generated isobenzopyrylium $\mathbf{8 A}$. Meanwhile, the ruthenium-diamine catalyst $\mathbf{1 3}$ reacted with dihydrogen to produce Ru$\mathrm{H}$ complex $\mathbf{8 C}$ and $\mathrm{TfOH}$. Then protonolysis of the $\mathrm{C}-\mathrm{Cu}$ bond of $\mathbf{8 A}$ by $\mathrm{TfOH}$ regenerated $\mathrm{Cu}(\mathrm{OTf})_{2}$ and gave another isobenzopyrylium intermediate $\mathbf{8 B}$. Finally, hydride transfer from the Ru-H complex $\mathbf{8 C}$ to isobenzopyrylium intermediate $\mathbf{8 B}$ afforded the desired product $\mathbf{1 2}$ and regenerated the ruthenium-diamine catalyst 13.

\section{Asymmetric Nucleophilic Addition}

Following the electrophilic cyclization of o-alkynylaryl carbonyl compounds, nucleophilic addition reactions at the 1-position of isobenzopyrylium ions have been demonstrated as another efficient method for the construction of 1 -substituted $1 \mathrm{H}$-isochromene derivatives. A wide variety of nucleophiles involving oxygen, ${ }^{73-76}$

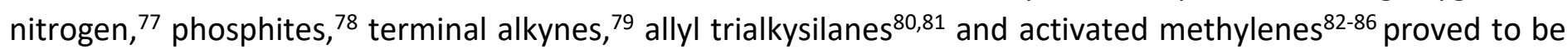
applicable substrates. And recently, (hetero)aromatics also can be used as good external nuclophiles. ${ }^{87-90}$ Nevertheless, their asymmetric version remains underdeveloped. Thus far, the reported asymmetric nucleophilic addition of isobenzopyrylium has been limited only to the addition of alcohols and activated methylene compounds. 
In 2012, Slaughter and co-workers achieved asymmetric formation of chiral 1-alkoxyisochromenes through the enantioselective addition of alcohols to isobenzopyryliums in the presence of a gold(I) acyclic diaminocarbene complex (Scheme 9). ${ }^{74}$ Owing to the ability of gold(I) to activate a variety of unsaturated bonds toward nucleophilic attack, catalysis with gold has emerged as a powerful tool for the synthesis of complex organic structures in the last decades. ${ }^{91-96}$ But its linear coordination geometry resulted in the remoteness of chiral ligand substituents and the inability of substrates to adopt a chelate binding mode that favoured asymmetric induction, which represented challenges to developing enantioselective catalysis. ${ }^{97-100}$ However, in some intriguing reports, the secondary interactions of ligands-Au were found to be helpful to overcome the inherent difficulty of achieving chiral environment, and thus high enantioselective results have been achieved with gold catalysts in some asymmetric reactions. ${ }^{101}$ Encouraged by these findings, Slaughter's group firstly created three gold acyclic diaminocarbene complexes 14-16, and then investigated their solidstate structural differences through their X-ray crystal structures. Compared with 14 and 15, a significantly more pronounced chiral environment at the metal center was observed in $\mathbf{1 6}$ owing to the presence of the aryl group adjacent to Au. This difference was directly reflected on the ability of chiral induction. Only with gold complex 16 were good yields and high enantioselectivities attained. However, for alcohols containing shorter $n$-alkyl chains or alkynes containing $n$-propyl instead of an aryl group, a new Au(I)/ADC complex 17 must be employed for ideal results. The chiral amine substituent in this modified catalyst $\mathbf{1 7}$ was believed to augment the chiral environment at the metal through steric interactions with the binaphthyl moiety.

The asymmetric addition reactions of $C$-nucleophiles to isobenzopyrylium ions at the 1-position provided a straight route to structurally diverse chiral 1-substituted $1 \mathrm{H}$-isochromene derivatives. ${ }^{102-104}$ In 2016 , the Enders group demonstrated the type of asymmetric addition could be realized under a combination of $\mathrm{Ag}_{2} \mathrm{CO}_{3}$ and chiral phosphoric acid, but only with moderate success (Scheme 10a). ${ }^{105}$ Just recently, Peng and his co-workers disclosed an efficient asymmetric addition of isobenzopyrylium with diazomethylphosphonate as $C$ nucleophile (Scheme 10b). ${ }^{106}$ Considering that transition-metal catalyst was still attached to the isobenzopyrylium ion at the 4-position after it activated the alkyne bond to conduct the intramolecular cyclization, the authors surmised that it could be exploited to create a chiral environment. The central metal coordinated with a chiral ligand possessing a sufficiently long arm, which might pass on chiral environment proximity to the 1-position, and thus, asymmetric nucleophile addition could be achieved at this position. Under the guidance of this assumption, chiral BOXes were chosen as promising ligands, because the chiral BOXes with different long arms could be easily prepared by using different chiral starting materials. ${ }^{107-110}$ The results of ligand screening showed that the BOXes with a cyclic ring at the bridging carbon gave better stereoselectivity than these with simple substituents, and the substituents at the 4,4'-position of the ligand also had a great effect on the catalytic performance. Ultimately, bis(oxazoline) ligand $\mathbf{1 8}$ combining with AgOTf was established as the optimal catalytic system. A variety of functional phosphine-containing isochromenes derivatives bearing tetrasubstituted stereocenters at the 1-position were easily prepared with up to $94 \%$ enantiomeric excess. The deuterium labeling experiment and DFT calculation were further performed to get more insight into the reaction mechanism. The steric hindrance between the isobenzopyrylium and attacking diazomethylphosphonate affected the facial coordination of $\mathrm{Ag}(\mathrm{I})$ and chiral ligand, which was considered to be the main reason for the satisfactory stereoselectivity. 


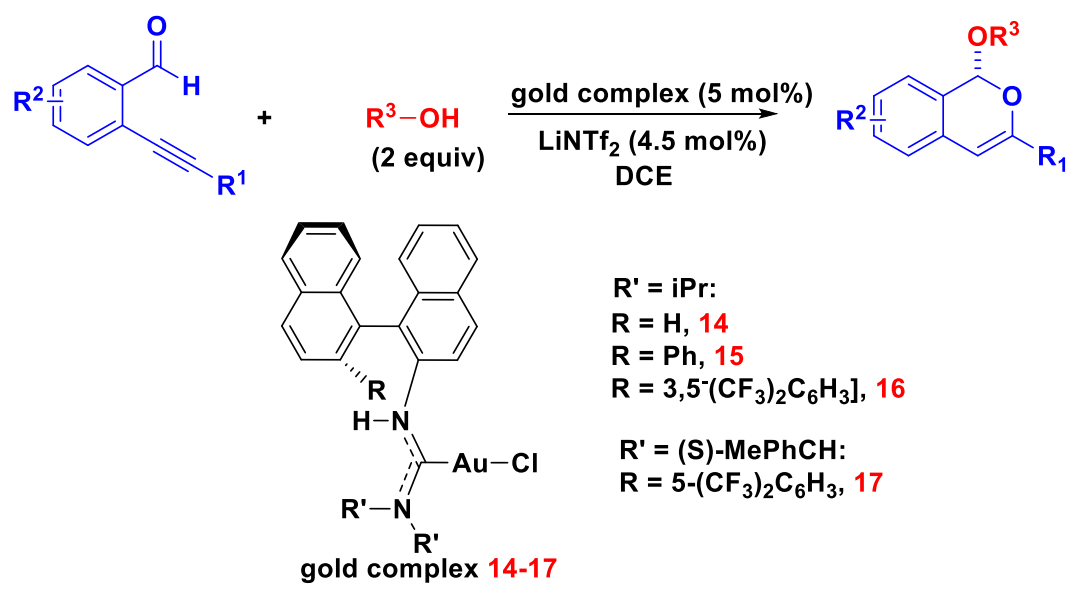

Scheme 9. Asymmetric nucleophilic addition of alcohols to isobenzopyrylium.

a) The Enders' work

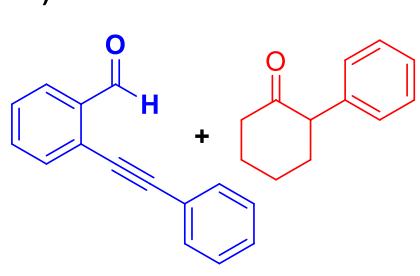

b) The Peng's work $2.5 \mathrm{~mol} \% \mathrm{Ag}_{2} \mathrm{CO}_{3}$
$\frac{10 \mathrm{~mol} \%(R)-T r i p}{\mathrm{n} \text {-hexane }}$
$40^{\circ} \mathrm{C}, 0.5 \mathrm{~h}$; then $0^{\circ} \mathrm{C}, 3 \mathrm{~d}$

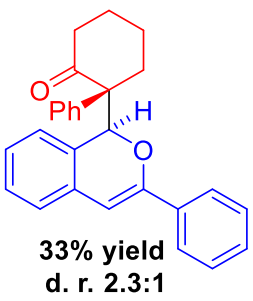

$63 \%$ ee

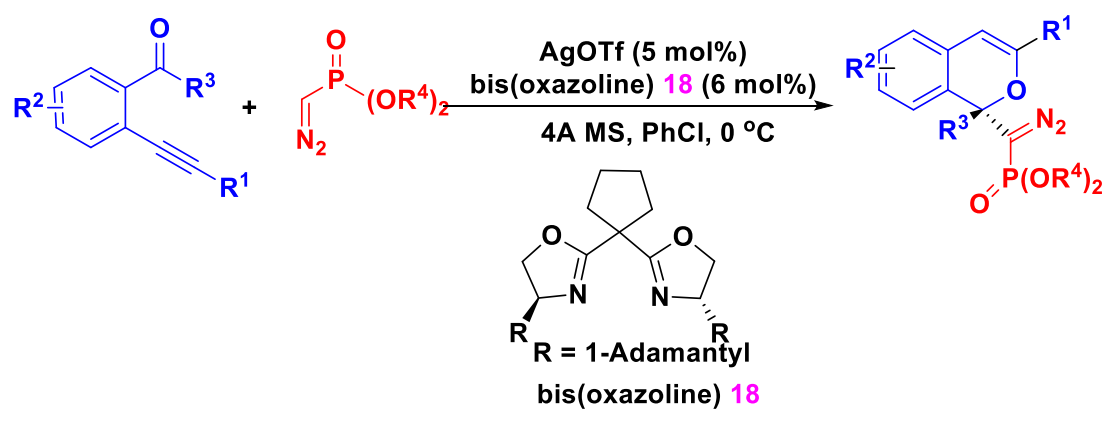

Scheme 10. Asymmetric $C$-nucleophilic addition to isobenzopyryliums.

\section{Conclusions}

Although the planar aromatic structure of isobenzopyrylium intermediates posed great challenges to their asymmetric transformations, many asymmetric reactions have been achieved with good to excellent diastereoselectivities by asymmetric counterion-directed catalysis, cooperative catalysis or unusual chiral ligands in recent years. And thus, a series of optically pure $1 H$-isochromene derivatives, 1,2dihydronaphthalenes or complex polycyclic compounds could be obtained in efficient and straightforward manners through asymmetric hydrogenation, asymmetric nucleophilic addition and asymmetric [4+2] cycloaddition and related cascade reactions. Inspired by these works, we believe that more interesting asymmetric reactions will be disclosed, such as asymmetric [3+2] cycloaddition reactions which remain unexplored in this stage. 


\section{Acknowledgements}

We are grateful to the support from the Doctoral Research Fund of Zhengzhou University of Light Industry (2014BSJJ009), Young Key Teachers of Zhengzhou University of Light Industry (2019XGGJS010), the National Natural Science Foundation of China (21602207) and the Foundation of Henan Educational Committee (21A530010)

\section{References}

1. Kuznetsov, E. V.; Shcherbakova, I. V.; Balaban, A. T. Adv. Heterocycl. Chem. 1990, 50, 157. https://doi.org/10.1016/S0065-2725(08)60063-X

2. Hein, S. J.; Lehnherr, D.; Arslan, H.; Uribe-Romo, F. J.; Dithtel, W. R. Acc. Chem. Res. 2017, $50,2776$. https://doi.org/10.1021/acs.accounts.7b00385

3. Shriner, R. L.; Johnston, H. W.; Kaslow, C. E. J. Org. Chem. 1949, 14, 204. https://doi.org/10.1021/jo01154a003

4. Asao, N.; Yamamoto, Y.; et al. J. Am. Chem. Soc. 2002, 124, 12650. https://doi.org/10.1021/ja028128z

5. Asao, N.; Nogami, T.; Lee, S.; Yamamoto, Y. J. Am. Chem. Soc. 2003, 125, 10921. https://doi.org/10.1021/ja036927r

6. Dyker, G.; Hildebrandt, D.; Liu, J. H. Angew. Chem., Int. Ed. 2003, 42, 4399. https://doi.org/10.1002/anie.200352160

7. Asao, N.; Aikawa, H.; Yamamoto, Y. J. Am. Chem. Soc. 2004, 126, 7458. https://doi.org/10.1021/ja0477367

8. Kim, N.; Kim, Y.; Park, W.; Sung, D.; Gupta, A. K.; Oh, C. H. Org. Lett. 2005, 7, 5289. https://doi.org/10.1021/ol052229v

9. Asao, N.;Kasahara, T.; Yamamoto, Y. Angew. Chem., Int. Ed. 2003, 42, 3504. https://doi.org/10.1002/anie.200351390

10. Patil, N. T.; Yamamoto, Y. J. Org. Chem. 2004, 69, 5139. https://doi.org/10.1021/jo049416b

11. Maeyama, K.; Iwasawa, N. J. Am. Chem. Soc. 1998, 120, 1928.

https://doi.org/10.1021/ja973317g

12. Iwasawa, N.; Shido, M.; Maeyama, K.; Kusama, H. J. Am. Chem. Soc. 2000, 122, 10226. https://doi.org/10.1021/ja001481p

13. Iwasawa, N.; Shido, M.; Kusama, H. J. Am. Chem. Soc. 2001, 123, 5814. https://doi.org/10.1021/ja010478i

14. Kusama, H.; Funami, H.; Shido, M.; Iwasawa, N. J. Am. Chem. Soc. 2005, 127, 2709. https://doi.org/10.1021/ja044194k

15. Asao, N.; Nogami, T.; Takahashi, K.; Yamamoto, Y. J. Am. Chem. Soc., 2002, 124, 764. https://doi.org/10.1021/ja017366b

16. Nakamura, H.; Ohtaka, M.; Yamamoto, Y. Tetrahedron Lett. 2002, 43, 7631. https://doi.org/10.1016/S0040-4039(02)01604-0

17. Mondal, S.; Nogami, T.; Asao, N.; Yamamoto, Y. J. Org. Chem. 2003, 68, 9496. https://doi.org/10.1021/jo035016x

18. Kusama, H.; Funami, H.; Takaya, J.; Iwasawa, N. Org. Lett. 2004, 6, 605. 
https://doi.org/10.1021/ol0364024

19. Bruneau, C. Angew. Chem., Int. Ed. 2005, 44, 2328.

https://doi.org/10.1002/anie.200462568

20. Hildebrandt, D.; Hüggenberg, W.; Kanthak, M.; Dyker, G. Chem. Commun. 2006, 2260.

https://doi.org/10.1039/B602498J

21. Kusama, H.; Ishida, K.; Funami, H.; Iwasawa, N. Angew. Chem., Int. Ed. 2008, 47, 4903.

https://doi.org/10.1002/anie.200705129

22. Hsu, Y. C.; Ting, C. M.; Liu, R. S. J. Am. Chem. Soc. 2009, 131, 2090.

https://doi.org/10.1021/ja809560c

23. Shin, S.; Gupta, A.-K.; Rhim, C.-Y.; Oh, C.-H. Chem. Commun. 2005, 4429.

https://doi.org/10.1039/B506003F

24. Yanada, R.; Hashimoto, K.; Tokizane, R.; Miwa, Y.; Minami, H.; K. Yanada, K.; M. Ishikura, M.; Takemoto, Y. J. Org. Chem. 2008, 73, 5135.

https://doi.org/10.1021/j0800474c

25. Selvi, T.; Srinivasan, K. Org. Biomol. Chem. 2013, 11, 2162.

https://doi.org/10.1039/C30B26284G

26. Sakthivel, K.; Srinivasan, K. Org. Biomol. Chem. 2014, 12, 269.

https://doi.org/10.1039/C30B41439F

27. Yue, D. W.; Della Cà, N.; Larock, R. C. Org. Lett. 2004, 6, 1581.

https://doi.org/10.1021/ol049690s

28. Patil, N. T.; Konala, A.; Singh, V.; Reddy, V. V. N. Eur. J. Org. Chem. 2009, 30, 5178.

https://doi.org/10.1002/ejoc.200900809

29. Sakthivel, K.; Srinivasan, K. Eur. J. Org. Chem. 2011, 32, 2781.

https://doi.org/10.1002/ejoc.201001746

30. Barluenga, J.; Vázquez-Villa, H.; Ballesteros, A.; González, J. M. J. Am. Chem. Soc. 2003, 125, 9028. https://doi.org/10.1021/ja0355372

31. Barluenga, J.; Vázquez-Villa, H.; Ballesteros, A.; González, J. M. Adv. Synth. Catal. 2005, 347, 526.

https://doi.org/10.1002/adsc.200404293

32. Barluenga, J.; Vázquez-Villa, H.; Merino, I.; Ballesteros, A.; González, J. M. Chem. Eur. J. 2006, $12,5790$. https://doi.org/10.1002/chem.200501505

33. Tovar, J. D.; Swager, T. M. J. Org. Chem. 1999, 64, 6499.

https://doi.org/10.1021/jo990810x

34. Sato, K.; Menggenbateer; Kubota, T.; Asao, N. Tetrahedron 2008, 64, 787.

https://doi.org/10.1016/i.tet.2007.10.083

35. Guo, B.; Zhou, Y. M.; Zhang, L.; Hua, R. M. J. Org. Chem. 2015, 80, 7635.

https://doi.org/10.1021/acs.joc.5b01219

36. Hu, Z. L.; Qian, W. J.; Wang, S.; Wang, S, Z.; Yao, Z. J. Org. Lett. 2009, 11, 4676.

https://doi.org/10.1021/ol9019524

37. Hu, Z. L.; Qian, W. J.; Yao, Z. J. Sci. China Chem. 2010, 53, 869.

https://doi.org/10.1007/s11426-010-0129-5

38. Hu, Z. L.; Qian, W. J.; Wang, S.; Wang, S. Z.; Yao, Z. J. J. Org. Chem. 2009, 74, 8787. https://doi.org/10.1021/jo902051g

39. Hu, Z. L.; Yang, Z. Y.; Wang, S. Z.; Yao, Z. J. Chem. Eur. J. 2011, 17, 1268. https://doi.org/10.1002/chem.201002317 
40. Kim, J. H.; Ray, D.; Hong, C. S.; Han, J. W.; Oh, C. H. Chem. Commun. 2013, 49, 5690. https://doi.org/10.1039/C3CC42525H

41. Chen, G. G.; Wei, J. Q.; Yang, X. L.; Yao, Z. J. Org. Lett. 2016, 18, 1502. https://doi.org/10.1021/acs.orglett.6b00010

42. Yu, S. Y.; Hu, Z. L.; Zhang, H.; Wang, S. Z.; Yao, Z. J. Tetrahedron Lett. 2012, 53, 2765. https://doi.org/10.1016/j.tetlet.2012.03.106

43. Mo, L.; Wu, L. L.; Wang, S. Z.; Yao, Z. J. Org. Lett. 2015, 17, 3314. https://doi.org/10.1021/acs.orglett.5b01532

44. Wu, A.; Qian, H.; Zhao, W. X.; Sun, J. W. Chem. Sci. 2020, 11, 7957. https://doi.org/10.1039/D0SC02502J

45. Chen, J. R.; Hu, X. Q.; Xiao, W. J. Angew. Chem. Int. Ed. 2014, 53, 4038. https://doi.org/10.1002/anie.201400018

46. Hojo, D.; Noguchi, K.; Tanaka, K. Angew. Chem. Int. Ed. 2009, 48, 8129. https://doi.org/10.1002/anie.200904024

47. Hojo, D.; Noguchi, K.; Hirano, M.; Tanaka, K. Angew. Chem. Int. Ed. 2008, 47, 5820. https://doi.org/10.1002/anie.200801642

48. Feringa, B. L.; van Delden, R. A.; Koumura, N.; Geertsema, E. M. Chem. Rev. 2000, 100, 1789. https://doi.org/10.1021/cr9900228

49. Yu, Y. S.; Zhao, H.; Gao, Y.; Mo, L.; Wang, S. Z.; Yao, Z. J. J. Am. Chem. Soc. 2013, 135, 11402. https://doi.org/10.1021/ja405764p

50. Stadler, D.; Bach, T. Angew. Chem., Int. Ed. 2008, 47, 7557. https://doi.org/10.1002/anie.200802611

51. Ward, R.-S. Nat. Prod. Rep. 1999, 16, 75. https://doi.org/10.1039/A705992B

52. Ward, R. S. Nat. Prod. Rep. 1997, 14, 43. https://doi.org/10.1039/NP9971400043

53. Nono, E. C. N.; Mkounga, P.; Kuete, V.; Marat, K.; Hultin, P. G.; Nkengfack, A. E. J. Nat. Prod. 2010, 73, 213.

https://doi.org/10.1021/np9007393

54. Nieto-Oberhuber, C.; Lopez, S.; Echavarren, A. M. J. Am. Chem. Soc. 2005, 127, 6178. https://doi.org/10.1021/ja042257t

55. Tenaglia, A.; Marc, S.; Giordano, L.; De Riggi, I. Angew. Chem. Int. Ed. 2011, 50, 9062. https://doi.org/10.1002/anie.201104589

56. Zhu, S.; Liang, R.; Jiang, H.; Wu, W. Angew. Chem. Int. Ed. 2012, 51, 10861. https://doi.org/10.1002/anie.201204798

57. Tomioka, K.; Shindo, M.; Koga, K. J. Am. Chem. Soc. 1989, 111, 8266. https://doi.org/10.1021/ja00203a032

58. Engelhardt, U.; Sarkar, A.; Linker, T. Angew. Chem. Int. Ed. 2003, 42, 2487. https://doi.org/10.1002/anie.200351086

59. Qian, H.; Zhao, W. X.; Wang, Z. B.; Sun, J. W. J. Am. Chem. Soc. 2015, 137, 560. https://doi.org/10.1021/ja509824j

60. Lin, Y. L.; Shen, C.C.; Huang, Y.J.; Chang, Y. Y. J. Nat. Prod. 2005, 68, 381. https://doi.org/10.1021/np0401819

61. Gao, J. M.; Yang S. X.; Qin, J. C. Chem. Rev. 2013, 113, 4755. 
https://doi.org/10.1021/cr300402y

62. Brown, C. W.; Liu, S.; Klucik, J.; Berlin, K. D.; Brennan, P. J.; Kaur, D.; Benbrook, D. M. J. Med. Chem. 2004, 47, 1008.

https://doi.org/10.1021/jm0303453

63. Hiroya, K.; Jouka, R.; Kameda, M.; Yasuhara, A.; Sakamoto, T. Tetrahedron 2001, 57, 9697. https://doi.org/10.1016/S0040-4020(01)00991-7

64. Gabriele, B.; Salerno, G.; Fazio, A.; Pittelli, R. Tetrahedron 2003, 59, 6251.

https://doi.org/10.1016/S0040-4020(03)01019-6

65. Saito, K.; Kajiwara, Y.; Akiyama, T. Angew. Chem. Int. Ed. 2013, 52, 13284.

https://doi.org/10.1002/anie.201308303

66. Mahlau, M.; List, B. Angew. Chem., Int. Ed. 2013, 52, 518.

https://doi.org/10.1002/anie.201205343

67. Phipps, R. J.; Hamilton, G. L.; Toste, F. D. Nat. Chem. 2012, 4, 603.

https://doi.org/10.1038/nchem.1405

68. Terada, M.; Li, F.; Toda, Y. Angew. Chem. Int. Ed. 2014, 53, 235.

https://doi.org/10.1002/anie.201307371

69. Zhou, H.; Li, Z.; Wang, Z.; Wang, T.; Xu, L.; He, Y. M.; Fan, Q. H.; Pan, J.; Gu, L.; Chan, A. S. C. Angew. Chem., Int. Ed. 2008, 47, 8464.

https://doi.org/10.1002/anie.200802237

70. Wang, T.; Chen, F.; Qin, J.; He, Y. M.; Fan, Q. H. Angew. Chem. Int. Ed. 2013, 52, 7172.

https://doi.org/10.1002/anie.201301830

71. Yang, Z.; Chen, F.; He, Y. M.; Yang, N.; Fan, Q. H. Angew. Chem. Int. Ed. 2016, 55, 13863. https://doi.org/10.1002/anie.201607890

72. Miao, T. T.; Tian, Z. Y.; He, Y. M.; Chen, F.; Chen, Y.; Yu, Z. X.; Fan, Q. H. Angew. Chem. Int. Ed. 2017, 56, 4135.

https://doi.org/10.1002/anie.201611291

73. Godet, T.; Vaxelaire, C.; Michel, C.; Milet, A.; Belmont, P. Chem. Eur. J. 2007, 13, 5632.

https://doi.org/10.1002/chem.200700202

74. Handa, S.; Slaughter, L. M. Angew. Chem. Int. Ed. 2012, 51, 2912.

https://doi.org/10.1002/anie.201107789

75. Kotera, A.; Uenishi, J. I.; Uemura, M. Tetrahedron Lett. 2010, 51, 1166. https://doi.org/10.1016/j.tetlet.2009.12.052

76. Liu, L-P.; Hammond, G. B. Org. Lett. 2010, 12, 4640.

https://doi.org/10.1021/ol101985d

77. Verma, A. K.; Choudhary, D.; Saunthwal, R. K.; Rustagi, V.; Patel, M.; Tiwari, R. K. J. Org. Chem. 2013, 78, 6657.

https://doi.org/10.1021/j04009639

78. Yu, X.; Ding, Q.; Wang, W.; Wu, J. Tetrahedron Lett. 2008, 49, 4390.

https://doi.org/10.1016/j.tetlet.2008.05.009

79. Yao, X.; Li, C-J. Org. Lett. 2006, 8, 1953.

https://doi.org/10.1021/ol060645p

80. Bhunia, S.; Wang, K-C.; Liu, R-S. Angew. Chem., Int. Ed. 2008, 47, 5063. https://doi.org/10.1002/anie.200800826

81. Asao, N.; Chan, C. S.; Takahashi, K.; Yamamoto, Y. Tetrahedron 2005, 61, 11322. 
https://doi.org/10.1016/i.tet.2005.09.012

82. Beeler, A. B.; Su, S.; Singleton, C. A.; Porco Jr., J. A. J. Am. Chem. Soc. 2007, 129, 1413. https://doi.org/10.1021/ja0674744

83. Malhotra, D.; Liu, L-P.; Mashuta, M. S.; Hammond, G. B. Chem. Eur. J. 2013, 19, 4043. https://doi.org/10.1002/chem.201203841

84. Obika, S.; Kono, H.; Yasui, Y.; Yanada, R.; Takemoto, Y. J. Org. Chem. 2007, 72, 4462. https://doi.org/10.1021/jo070615f

85. Yu, S. Y.; Gao, L. H.; Wu, J. X.; Lan, H. B.; Ma, Y.; Yin, Z. G. Chem. Pap. 2020, 74, 3303. https://doi.org/10.1007/s11696-020-01159-5

86. Li, F. H.; Li, J.; Wang, S. Y.; Ji, S. J. Tetrahedron 2017, 73, 5731. https://doi.org/10.1016/j.tet.2017.07.051

87. Mariaule, G.; Newsome, G.; Toullec, P. Y.; Belmont, P.; Michelet, V. Org. Lett. 2014, 16, 4570. https://doi.org/10.1021/ol5021256

88. Tang, R-Y.; Li, J. H. Chem. Eur. J. 2010, 16, 4733. https://doi.org/10.1002/chem.201000133

89. Toullec, P. Y.; Genin, E.; Leseurre, L.; Genêt, J. P.; Michelet, V. Angew. Chem., Int. Ed. 2006, 45, 7427. https://doi.org/10.1002/anie.200601980

90. Qiu, G.; Liu T.; Ding, Q. Org. Chem. Front. 2016, 3, 510.

https://doi.org/10.1039/C6Q000041J

91. Dorel, R.; Echavarren, A. M. Chem. Rev. 2015, 115, 9028.

https://doi.org/10.1021/cr500691k

92. Pflasterer, D.; Hashmi, A. S. K. Chem. Soc. Rev. 2016, 45, 1331.

https://doi.org/10.1039/C5CS00721F

93. Jimenez-Nunez, E.; Echavarren, A. M. Chem. Commun. 2007, 4, 333. https://doi.org/10.1039/B612008C

94. Haruta, M. Nature 2005, 437, 1098. https://doi.org/10.1038/4371098a

95. Rudolph, M.; Hashmi, A. S. K. Chem. Commun. 2011, 47, 6536. https://doi.org/10.1039/C1CC10780A

96. Reyes, R. L.; Iwai, T.; Sawamura, M. Chem. Rev. 2020. https://doi.org/10.1021/acs.chemrev.0c00793

97. Sengupta, S.; Shi, X. D. ChemCatChem. 2010, 2, 609. https://doi.org/10.1002/cctc.201000070

98. Pradal, A.; Toullec, P. Y.; Michelet, V. Synthesis 2011, 10, 1501. https://doi.org/10.1055/s-0030-1258465

99. Widenhoefer, R. A. Chem. Eur. J. 2008, 14, 5382. https://doi.org/10.1002/chem.200800219

100. Mourad, A. S.; Czekelius, C. Synlett 2013, 24, 1459. https://doi.org/10.1055/s-0033-1338841

101. Teller, H.; Fuugge, S.; Goddard, R.; Furstner, A. Angew. Chem. Int. Ed. 2010, 49, 1949. https://doi.org/10.1002/anie.200906550

102. Yu, S. Y.; Gao, L. H.; Lan, H. B.; Qian, H. Y.; Yin, Z. G.; Shang, Y. J. Chin. J. Org. Chem. 2020, 40, 2714. https://doi.org/10.6023/cjoc202004034

103. Chauhan, P.; Tamanna, T.; Joshi, K.; Kumar, M. Adv. Synth. Catal. 2020, 362, 1907. 
https://doi.org/10.1002/adsc.202000243

104. Dell'Acqua, M.; Pirovano, V.; Peroni, S.; Tseberlidis, G.; Nava, D.; Rossi, E.; Abbiati, G. Eur. J. Org. Chem. 2017, 1425.

https://doi.org/10.1002/ejoc.201601602

105. Bröhl, N. F.; Kundu, D. S.; Raabe, G.; Enders, D. Synthesis 2017, 49, 1243.

https://doi.org/10.1055/s-0036-1588641

106. Cai, L.; Chen, Y.; Cao, H.; Wei, Q.; Yang, Y.; Ouyang, Q.; Peng, Y. G. Org. Lett. 2019, 21, 7597. https://doi.org/10.1021/acs.orglett.9b02864

107. Yu, S. Y.; Wu, J. X.; Lan, H. B.; Gao, L. H.; Qian, H. Y.; Fan, K. Q.; Yin, Z. G. Org. Lett. 2020, 22, 102. https://doi.org/10.1021/acs.orglett.9b04015

108. Desimoni, G.; Faita, G.; Jørgensen, K. A. Chem. Rev. 2011, 111, 284. https://doi.org/10.1021/cr100339a

109. Desimoni, G.; Faita, G.; Jørgensen, K. A. Chem. Rev. 2006, 106, 3561. https://doi.org/10.1021/cr0505324

110. Liu, L.; Ma, H. L.; Wu, Y. H.; Yuan, D. K.; Liu, J. P.; Fu, B.; Ma, X. D. Chin. J. Org. Chem. 2013, 33, 2283. https://doi.org/10.6023/cjoc201306001

\section{Authors' Biographies}

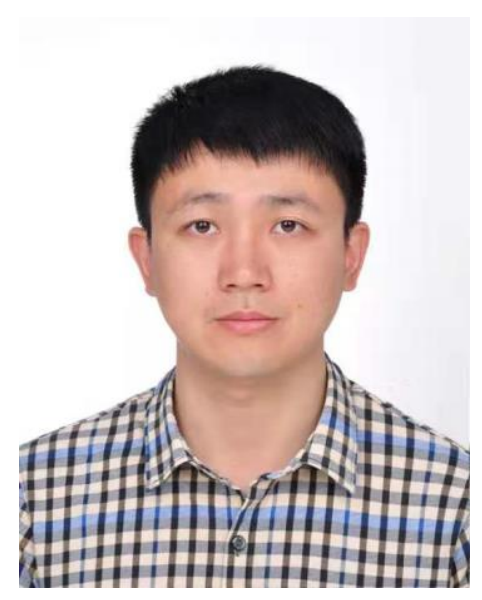

Hongbing Lan was born in Anhui province, China, in 1986. He is presently an assistant professor at Material and Chemical Engineering College, Zhengzhou University of Light Industry. He graduated with MSc from School of Chemistry and Chemical Engineering, Anhui University of Technology in 2008. And he received his BSc from college of chemical engineering, Nanjing Tech University. His research interests are design and synthesis of biologically active heterocyclic compounds. 


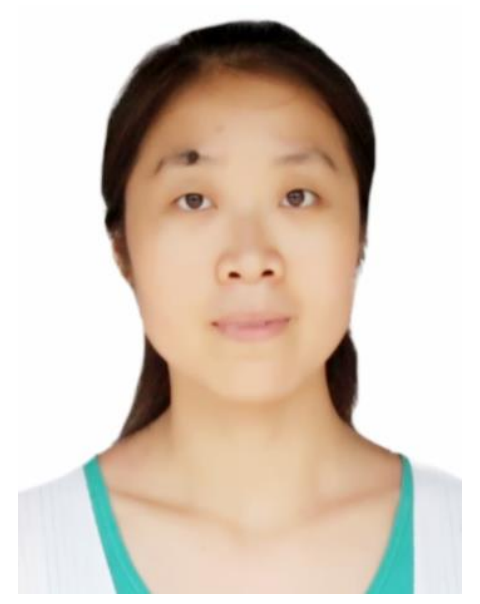

Shuyan Yu was born in Anhui province, China, in 1985. She is presently an assistant professor at Material and Chemical Engineering College, Zhengzhou University of Light Industry. She received her BSc and MSc degree in 2007 and 2010, respectively, in chemistry and organic chemistry from School of Chemistry and Materials Science, Anhui Normal Universty, Wuhu, Anhui province, China. She graduated with PhD degree in organic chemistry from Nanjing Universtity, Jiangsu provinve, China in 2013. Her research interests focus on the development of efficient methods for heterorcyclic compounds based on alkyne functionalization.

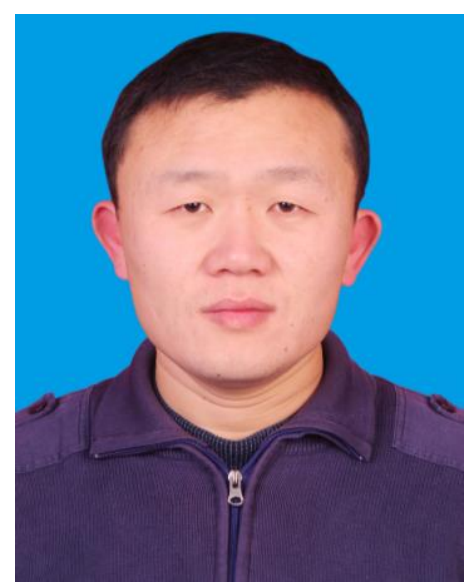

Hengyu Qian was born in Shandong province, China, in 1979. He is presently an associate professor at Material and Chemical Engineering College, Zhengzhou University of Light Industry. He graduated with BSc in chemistry from School of Chemistry and Chemical Engineering, Qufu Normal University in 2000. And then received Master's degree in organic chemistry at College of Chemistry, Zhengzhou University in 2004. His research interests focus on the synthesis of palladium complexes and their application in C-C cross-coupling reaction. 


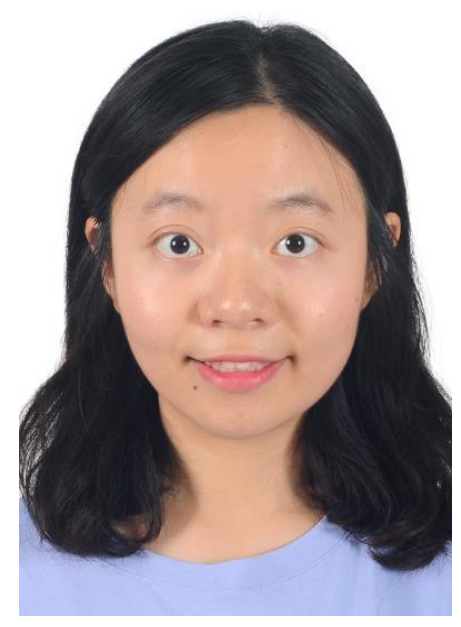

Weiyi Zhao was born in Guangdong Province, China, in 2000. She is currently an undergraduate a Material and Chemical Engineering College, Zhengzhou University of Light Industry. She always takes part in Professor Yin's research project in spare time.

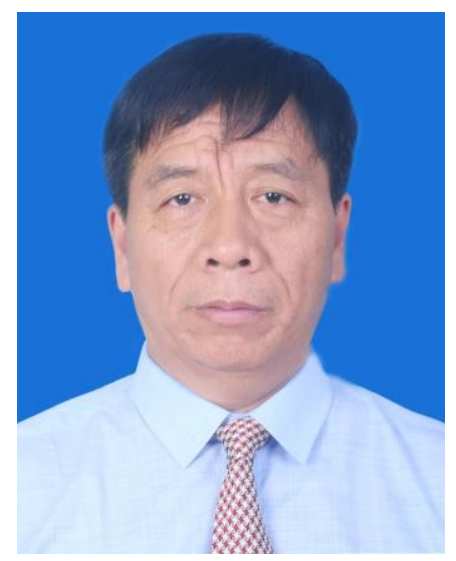

Zhigang Yin was born in Henan province, China, in 1965. He is presently a full professor at Material and Chemical Engineering College, Zhengzhou University of Light Industry. He graduated with BSc in organic chemistry from Zhengzhou University in 1985. And he received his PhD degree in fine chemicals in Dalian University of Technology in 2003. His research interests include synthesis and application of functional intermediates (including dye, medicine, liquid crystal display, and rubber vulcanization etc.) 